\section{UPDATE AleRT}

\section{Update Alert 5: Risks and Impact of Angiotensin-Converting Enzyme Inhibitors or Angiotensin-Receptor Blockers on SARS-CoV-2 Infection in Adults}

We searched MEDLINE (Ovid) weekly from 1 September to 28 September 2020 using the same search strategy as described in the original review (1). We did not limit the search by language. This search update yielded 77 results (de-duplicated), and after an independent dual-review process, we identified 15 new studies meeting our inclusion criteria-8 observational studies, 6 systematic reviews with meta-analyses, and 1 clinical trial protocol. New Evidence

Findings from 2 observational studies, 1 of which is an update of a previously published retrospective analysis of insurance data in South Korea, found no evidence of an association between angiotensin-converting enzyme inhibitor (ACEI) or angiotensin-receptor blocker (ARB) use and risk for coronavirus disease 2019 (COVID-19) (2, 3). This South Korean study and an additional 6 observational studies found no association between the use of ACEls or ARBs and COVID-19 disease severity (3-9). These studies include a retrospective analysis of the association of ACEI or ARB use on need for mechanical ventilation and mortality among a predominantly Hispanic/Latino and African American population in New York City treated for COVID-19 in March 2020, which, like prior studies, found no difference (4).

These findings are supported by 6 new systematic reviews with meta-analyses, except for 1 review finding a mildly increased risk for infection among patients younger than 60 years using ARBs (adjusted odds ratio, 1.09 [95\% Cl, 1.01 to 1.18]) $(10-15)$.

Overall, inclusion of 15 studies from this search update does not change the certainty of evidence rating we reported in the original manuscript for key questions 1 or 2 . Studies have not examined the benefits and harms of initiating ACEls or ARBs (that is, new users) in COVID-19 treatment; therefore, evidence for key question 3 remains unclear. In-Progress Trial

We identified 1 new in-progress trial evaluating hospitalrelated outcomes among adults admitted with COVID-19 who either continued or discontinued ACEls or ARBs (16).

Katherine Mackey, MD, MPP

Devan Kansagara, MD, MCR

Kathryn Vela, MLIS, AHIP

VA Portland Health Care System, Portland, Oregon

Disclaimer: The views expressed in this article are those of the authors and do not necessarily represent the views of the U.S. Department of Veterans Affairs or the U.S. government.

Disclosures: Authors have disclosed no conflicts of interest. Forms can be viewed at www.acponline.org/authors/icmje/ConflictOfInterest Forms.do?msNum=L20-1293.
Corresponding Author: Katherine Mackey, MD, MPP, VA Portland Health Care System, 3710 SW US Veterans Hospital Road, Portland, OR 97239; e-mail, Katherine.Mackey@va.gov.

doi:10.7326/L20-1293

\section{References}

1. Mackey K, King VJ, Gurley S, et al. Risks and impact of angiotensinconverting enzyme inhibitors or angiotensin-receptor blockers on SARS-CoV-2 infection in adults: a living systematic review. Ann Intern Med. 2020;173:195 203. [PMID: 32422062] doi:10.7326/M20-1515

2. Chodick G, Nutman A, Yiekutiel N, et al. Angiotensin-converting enzyme inhibitors and angiotensin-receptor blockers are not associated with increased risk of SARS-CoV-2 infection [Letter]. J Travel Med. 2020;27. [PMID: 32406512] doi:10.1093/jtm/taaa069

3. Seo J, Son M. Update on association between exposure to renin angiotensin-aldosterone system inhibitors and coronavirus disease 2019 in South Korea. Korean J Intern Med. 2020. [PMID: 32872736] doi:10.3904/kjim .2020 .380

4. Adrish $M$, Chilimuri $S$, Sun $H$, et al. The association of reninangiotensin-aldosterone system inhibitors with outcomes among a predominantly ethnic minority patient population hospitalized with COVID19: the Bronx experience. Cureus. 2020;12:e10217. [PMID: 32905551] doi:10.7759/cureus.10217

5. Anzola GP, Bartolaminelli C, Gregorini GA, et al. Neither ACEls nor ARBs are associated with respiratory distress or mortality in COVID-19 results of a prospective study on a hospital-based cohort. Intern Emerg Med. 2020. [PMID: 32965603] doi:10.1007/s11739-020-02500-2

6. Kocayigit I, Kocayigit $\mathrm{H}$, Yaylaci $\mathrm{S}$, et al. Impact of antihypertensive agents on clinical course and in-hospital mortality: analysis of 169 hypertensive patients hospitalized for COVID-19. Rev Assoc Med Bras (1992). 2020;66Suppl 2:7176. [PMID: 32965360] doi:10.1590/1806-9282.66.S2.71

7. Negreira-Caamaño M, Piqueras-Flores J, Martínez-DelRio J, et al. Impact of treatment with renin-angiotensin system inhibitors on clinical outcomes in hypertensive patients hospitalized with COVID-19. High Blood Press Cardiovasc Prev. 2020. [PMID: 32949380] doi:10.1007/s40292-020-00409-7

8. Soleimani A, Kazemian S, Karbalai Saleh S, et al. Effects of angiotensin receptor blockers (ARBs) on in-hospital outcomes of patients with hypertension and confirmed or clinically suspected COVID-19. Am J Hypertens. 2020 [PMID: 32920644] doi:10.1093/ajh/hpaa149

9. Wang $Z$, Zhang $D$, Wang $S$, et al. A retrospective study from 2 centers in China on the effects of continued use of angiotensin-converting enzyme inhibitors and angiotensin II receptor blockers in patients with hypertension and COVID-19. Med Sci Monit. 2020;26:e926651. [PMID: 32969367] doi:10 12659/MSM.926651

10. Caldeira D, Alves M, Gouveia E Melo R, et al. Angiotensin-converting enzyme inhibitors and angiotensin-receptor blockers and the risk of COVID-19 infection or severe disease: systematic review and meta-analysis. Int J Cardiol Heart Vasc. 2020;31:100627. [PMID: 32875060] doi:10.1016/j.ijcha.2020 .100627

11. Chan CK, Huang YS, Liao HW, et al; National Taiwan University Hospital Study Group of ARF, the Taiwan Primary Aldosteronism Investigators and the Taiwan Consortium for Acute Kidney Injury and Renal Diseases. Reninangiotensin-aldosterone system inhibitors and risks of severe acute respiratory syndrome coronavirus 2 infection: a systematic review and meta-analysis. Hypertension. 2020;76:1563-1571. [PMID: 32869673] doi: 10.1161/HYPERTENSIONAHA.120.15989

12. Greco $A$, Buccheri $S$, D'Arrigo $P$, et al. Outcomes of renin-angiotensinaldosterone system blockers in patients with COVID-19: a systematic review and meta-analysis [Letter]. Eur Heart J Cardiovasc Pharmacother. 2020;6:335337. [PMID: 32671399] doi:10.1093/ehjcvp/pvaa074

This article was published at Annals.org on 27 October 2020. 


\section{LETTERS}

13. Hasan SS, Kow CS, Hadi MA, et al. Mortality and disease severity among COVID-19 patients receiving renin-angiotensin system inhibitors: a systematic review and meta-analysis. Am J Cardiovasc Drugs. 2020. [PMID: 32918209] doi:10.1007/s40256-020-00439-5

14. Lo KB, Bhargav R, Salacup G, et al. Angiotensin converting enzyme inhibitors and angiotensin I| receptor blockers and outcomes in patients with COVID-19: a systematic review and meta-analysis. Expert Rev Cardiovasc Ther. 2020:1-12. [PMID: 32945216] doi:10.1080/14779072.2020.1826308
15. Patoulias D, Katsimardou A, Stavropoulos K, et al. Renin-angiotensin system inhibitors and COVID-19: a systematic review and meta-analysis. Evidence for significant geographical disparities. Curr Hypertens Rep. 2020;22:90 [PMID: 32910274] doi:10.1007/s11906-020-01101-w

16. Cohen JB, Hanff TC, Corrales-Medina V, et al. Randomized elimination and prolongation of ACE inhibitors and ARBs in coronavirus 2019 (REPLACE COVID) trial protocol. J Clin Hypertens (Greenwich). 2020. [PMID: 32937008] doi:10.1111/jch.14011 